OPEN ACCESS

Edited by:

Christian Celia,

University of Studies G. d'Annunzio

Chieti and Pescara, Italy

Reviewed by:

Xianwen Wang,

Anhui Medical University, China

Kai Yang,

Soochow University, China

*Correspondence: Kelong Ai

aikelong@csu.edu.cn

${ }^{\dagger}$ These authors have contributed equally to this work

Specialty section:

This article was submitted to Pharmacology of Anti-Cancer Drugs, a section of the journal

Frontiers in Pharmacology

Received: 27 December 2021

Accepted: 28 January 2022

Published: 18 February 2022

Citation:

Huang J, Huang Q, Liu M, Chen Q and Ai K (2022) Emerging Bismuth Chalcogenides Based Nanodrugs for

Cancer Radiotherapy.

Front. Pharmacol. 13:844037.

doi: 10.3389/fphar.2022.844037

\section{Emerging Bismuth Chalcogenides Based Nanodrugs for Cancer Radiotherapy}

\author{
Jia Huang ${ }^{1,2 \dagger}$, Qiong Huang ${ }^{3,4 \dagger}$, Min Liu $^{3,4}$, Qiaohui Chen ${ }^{1,2}$ and Kelong $\mathrm{Ai}^{1,2 *}$ \\ ${ }^{1}$ Xiangya School of Pharmaceutical Sciences, Central South University, Changsha, China, ${ }^{2}$ Hunan Provincial Key Laboratory of \\ Cardiovascular Research, Xiangya School of Pharmaceutical Sciences, Central South University, Changsha, China, ${ }^{3}$ Department \\ of Pharmacy, Xiangya Hospital, Central South University, Changsha, China, ${ }^{4}$ National Clinical Research Center for Geriatric \\ Disorders, Xiangya Hospital, Central South University, Changsha, China
}

Radiotherapy (RT), as one of the main methods of clinical tumor treatment, has been applied to the treatment of most solid tumors. However, the effect of RT is compromised by the radiation resistance of tumor hypoxic environment and non-specific damage caused by high-dose radiation. Bismuth chalcogenides $\left(\mathrm{Bi}_{2} \mathrm{X}_{3}, X=\mathrm{S}\right.$, Se) based nanodrugs have attracted widespread attention as highly efficient radiosensitizers due to their high photoelectric effect and excellent biocompatibility. More importantly, specially designed nanocomposites can effectively alleviate the radiation resistance of tumor tissues. Here, for the first time, we systematically summarize the latest progresses of $\mathrm{Bi}_{2} \mathrm{X}_{3}$ nanodrugs to enhance RT by alleviating the hypoxic tumor microenvironment. These emerging $\mathrm{Bi}_{2} \mathrm{X}_{3}$ nanodrugs mainly include three aspects, which $\operatorname{are} \mathrm{Bi}_{2} \mathrm{X}_{3}$ nanocomposites with high-efficient $\mathrm{O}_{2}$ supply, non- $\mathrm{O}_{2}$-dependent $\mathrm{Bi}_{2} \mathrm{X}_{3}$ nanocomposites $\mathrm{RT}$ enhancers, and $\mathrm{Bi}_{2} \mathrm{X}_{3}$ nanocomposites-based photothermal-enhanced radiosensitizers. These $\mathrm{Bi}_{2} \mathrm{X}_{3}$ nanodrugs can effectively overcome the RT resistance of tumor hypoxic microenvironment, and have extremely high therapeutic effects and clinical application prospects. Finally, we put forward the challenges and prospects of $\mathrm{Bi}_{2} \mathrm{X}_{3}$ nanomaterials in the field of $\mathrm{RT}$.

Keywords: bismuth chalcogenides, nanomaterials, cancer radiotherapy, radiosensitizers, tumor hypoxia microenvironment

\section{INTRODUCTION}

Radiotherapy (RT) has many advantages for cancer treatment compared with surgery or chemotherapy, like non-invasive, excellent targeting, and low cost (Begg et al., 2011). Currently, half of new cancers are treated with RT (Bentzen, 2006). RT adopts ionizing radiation (usually X-ray) to irradiate the tumor site through direct and indirect action to induce cancer cell death. Ionizing radiation can directly destroy DNA or protein by breaking the bonds in these molecules. More importantly, high-energy ionizing radiation can easily ionize and split $\mathrm{H}_{2} \mathrm{O}$ to produce many reactive oxygen species (ROS) in tumor tissues (Eq. 1) (Le Caër, 2011). These ROS further cause the death of cancer cells by damaging DNA and proteins (Wu et al., 2019; Yao et al., 2021a). This indirect effect is the main tumor-killing effect of RT because the water content is the highest (generally $65 \%$ ) in tumor tissues. However, there are two bottlenecks which greatly limit the effectiveness of RT. Firstly, a larger dose of X-rays is usually required to kill tumor cells because cancer tissues absorb X-rays very weakly, which also cause damage to normal tissues, especially the immune system (De Martino et al., 2021). Secondly, the hypoxic tumor microenvironment (TME) greatly 


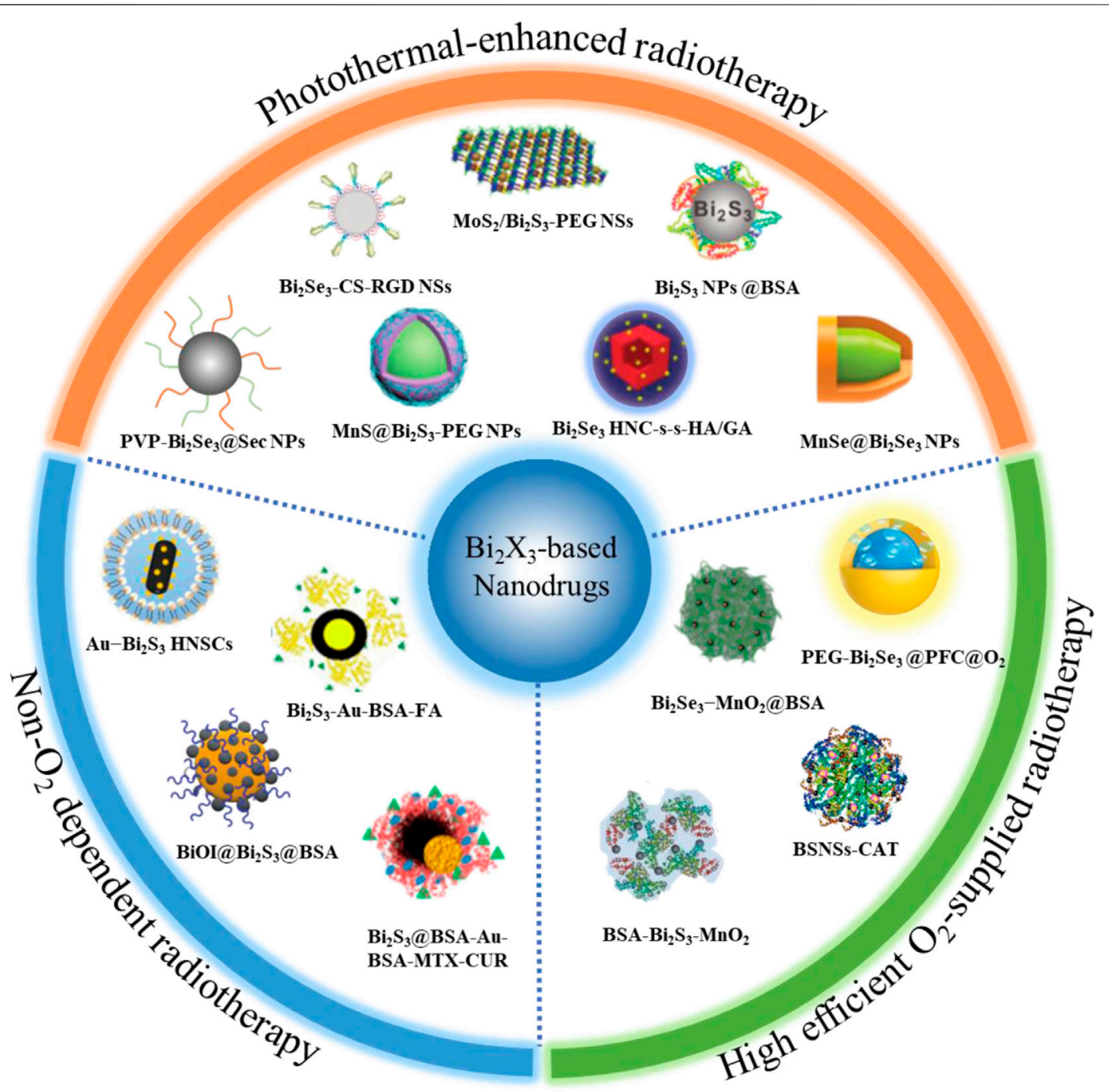

FIGURE 1 | Overview of radiosensitization strategies based on $\mathrm{Bi}_{2} \mathrm{X}_{3}$ nanodrugs, which mainly including three aspects, the first is high efficient $\mathrm{O}_{2}$-supplied $\mathrm{Bi}_{2} \mathrm{X}_{3}$ based nanodrugs: such as perfluorocarbon-loaded hollow $\mathrm{Bi}_{2} \mathrm{Se}_{3}$ nanoparticles ( $\mathrm{PEG}-\mathrm{Bi}_{2} \mathrm{Se}_{3} @ \mathrm{PFC} @ \mathrm{O}_{2} \mathrm{NPs}$ ), bismuth sulfide-albumin composite nanospheres

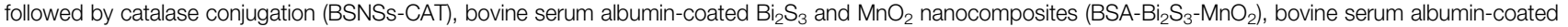
$\mathrm{Bi}_{2} \mathrm{Se}_{3}$ and $\mathrm{MnO}_{2}$ nanocomposites $\left(\mathrm{Bi}_{2} \mathrm{Se}_{3}-\mathrm{MnO}_{2} @ \mathrm{BSA}\right)$; the second is Non- $\mathrm{O}_{2}$ dependent $\mathrm{Bi}_{2} \mathrm{X}_{3}$-based nanodrugs: such as Schottky-type heterostructure of Au$\mathrm{Bi}_{2} \mathrm{~S}_{3}$ (Au-Bi $\mathrm{S}_{3} \mathrm{HNSCs}$ ), co-drug (MTX and CUR) loaded $\mathrm{Bi}_{2} \mathrm{~S}_{3} @ B S A-A u$ semiconductor-metal heterojunction nanoparticles (Bi $\left.\mathrm{B}_{2} @ B S A-A u-B S A-M T X-C U R\right)$, folic acid (FA) functionalized and $\mathrm{BSA}$-modified $\mathrm{Bi}_{2} \mathrm{~S}_{3}$-Au heterodimers $\left(\mathrm{Bi}_{2} \mathrm{~S}_{3}\right.$-Au-BSA-FA); the third is photothermal-enhanced $\mathrm{Bi}_{2} \mathrm{X}_{3}$-based nanodrugs, such as $\mathrm{PEGylated}$ $2 \mathrm{D} \mathrm{MoS} / \mathrm{Bi}_{2} \mathrm{~S}_{3}$ composite nanosheets ( $\mathrm{MoS}_{2} / \mathrm{Bi}_{2} \mathrm{~S}_{3}$-PEG NSs), BSA-stabilized $\mathrm{Bi}_{2} \mathrm{~S}_{3}$ Nanoparticles $\left(\mathrm{Bi}_{2} \mathrm{~S}_{3} \mathrm{NPs} @ \mathrm{BSA}\right)$, poly(vinylpyrollidone)-and selenocysteinemodified $\mathrm{Bi}_{2} \mathrm{Se}_{3}$ nanoparticles (PVP-Bi $\mathrm{Se}_{3} @ \mathrm{Sec} \mathrm{NPs}$ ), HA-functionalized gambogic acid (GA) loaded $\mathrm{Bi}_{2} \mathrm{Se}_{3}$ hollow nanocube (HNC-s-s-HA/GA) and MnSe@Bi $2 \mathrm{Se}_{3}$ core-shell nanoparticles (MnSe@Bi $\left.\mathrm{Se}_{3} \mathrm{NPs}\right)$.

reduces the effect of RT. $\mathrm{O}_{2}$ is a very important $\mathrm{RT}$ sensitizer and is easy to accept a free electron to form superoxide radicals $\left(\mathrm{O}_{2}{ }^{-} \cdot\right)$, which is then further converted into other highly oxidative active ROS (e.g. hydrogen peroxide and hydroxyl radicals) (Zhao et al., 2022; Zhu et al., 2022). Compared with normal cells, cancer cells are 3-times more resistant to RTinduced killing in a tumor hypoxia environment (Evans et al., 1997).

$$
\mathrm{H}_{2} \mathrm{O} \stackrel{\text { Ionizing Radiation }}{\longrightarrow} \mathrm{e}^{-}+\cdot \mathrm{OH}+\mathrm{H} \cdot+\mathrm{HO}_{2} \cdot+\mathrm{H}_{2} \mathrm{O}_{2}+\mathrm{H}_{3} \mathrm{O}^{+}+\mathrm{HO}^{-}
$$

Drugs containing high atomic number elements can be very effective in enhancing RT because they have a much higher X-ray absorption capacity than human tissues. Currently, many kinds of elements with high atomic number have been researched for radiosensitization, such as $\mathrm{Au}, \mathrm{Ta}, \mathrm{W}, \mathrm{Yb}, \mathrm{Hf}$, and $\mathrm{Bi}$ (Tang et al., 2019; Xie et al., 2019; Zang et al., 2019; Peng et al., 2020; Liu et al., 2021; Xue et al., 2021). For example, NBTXR3 based on $\mathrm{HfO}_{2}$ has been approved by the FDA to enter Phase III clinical studies, and demonstrated excellent RT effect for advanced soft-tissue sarcoma (Bonvalot et al., 2019). However, most of the high- $Z$ elements are heavy metal elements with high toxicity, and their 
TABLE 1 | The overview of emerging $\mathrm{Bi}_{2} \mathrm{X}_{3}$-based nanodrugs for $\mathrm{RT}$.

\begin{tabular}{|c|c|c|c|}
\hline Category & Nanomaterials & Advantages of nanomaterials & Ref \\
\hline \multirow[t]{4}{*}{$\begin{array}{l}\text { High efficient } \mathrm{O}_{2} \text {-supplied } \\
\text { radiotherapy }\end{array}$} & PEG-Bi $\mathrm{Se}_{3} @ \mathrm{PFC} @ \mathrm{O}_{2}$ NPs & $\begin{array}{l}\text { Efficient oxygen carrying capacity; powerful radiosensitization } \\
\text { performance }\end{array}$ & $\begin{array}{l}\text { Song et al. } \\
(2016)\end{array}$ \\
\hline & $\mathrm{BSA}-\mathrm{Bi}_{2} \mathrm{~S}_{3}-\mathrm{CAT} \mathrm{NSs}$ & Effective tumor homing and tumor hypoxia relief & $\begin{array}{l}\text { Zhang et al. } \\
(2018)\end{array}$ \\
\hline & $\mathrm{Bi}_{2} \mathrm{Se}_{3}-\mathrm{MnO}_{2}-\mathrm{BSA}$ & $\begin{array}{l}\text { Excellent CAT-like catalytic activity; high colloidal stability and } \\
\text { biocompatibility }\end{array}$ & $\begin{array}{l}\text { Yao et al. } \\
(2021 b)\end{array}$ \\
\hline & $\mathrm{BSA}-\mathrm{Bi}_{2} \mathrm{~S}_{3}-\mathrm{MnO}_{2}$ & $\begin{array}{l}\text { Remarkable radiotherapeutic enhancement effect; without obvious toxic } \\
\text { and side effects }\end{array}$ & $\begin{array}{l}\text { Zhang et al. } \\
\text { (2019) }\end{array}$ \\
\hline \multirow[t]{3}{*}{$\begin{array}{l}\text { Non- } \mathrm{O}_{2} \text { dependent } \\
\text { radiotherapy }\end{array}$} & Schottky-type heterostructure of $\mathrm{Au}-\mathrm{Bi}_{2} \mathrm{~S}_{3}$ & $\begin{array}{l}\text { Significant electron-hole separation efficiency, high-efficiency } \\
\text { radiosensitization properties }\end{array}$ & $\begin{array}{l}\text { Wang et al. } \\
(2019)\end{array}$ \\
\hline & $\mathrm{Bi}_{2} \mathrm{~S}_{3} @ B S A-A u-B S A-M T X-C U R$ hybrid system & $\begin{array}{l}\text { Efficient electron-hole separation efficiency and synergistic anti-tumor } \\
\text { effects of radio-chemotherapy }\end{array}$ & $\begin{array}{l}\text { Nosrati et al. } \\
(2022)\end{array}$ \\
\hline & $\mathrm{Bi}_{2} \mathrm{~S}_{3}-\mathrm{Au}-\mathrm{BSA}-\mathrm{FA}$ hybrids & Effective radiosensitization and tumor targeting & $\begin{array}{l}\text { Abhari et al. } \\
(2020)\end{array}$ \\
\hline \multirow[t]{10}{*}{$\begin{array}{l}\text { Photothermal-enhanced } \\
\text { radiotherapy }\end{array}$} & $\mathrm{Bi}_{2} \mathrm{~S}_{3}$ nanorods & Remarkable radio-photothermal synergistic therapeutic effect & $\begin{array}{l}\text { Cheng et al. } \\
(2017)\end{array}$ \\
\hline & BSA-capped $\mathrm{Bi}_{2} \mathrm{~S}_{3} \mathrm{NPS}$ & $\begin{array}{l}\text { Ultra-small size; remarkable } X \text {-ray and photothermal response properties } \\
(\eta=51 \%)\end{array}$ & $\begin{array}{l}\text { Wang et al. } \\
(2016)\end{array}$ \\
\hline & $\mathrm{BSA}-\mathrm{Bi}_{2} \mathrm{Se}_{3}$ nanodots & $\begin{array}{l}\text { High photothermal conversion efficiency }(\eta=50.7 \%) \text {; effective } \\
\text { radiosensitization ratio }(6 \%)\end{array}$ & $\begin{array}{l}\text { Mao et al. } \\
(2016)\end{array}$ \\
\hline & $\mathrm{PVP}-\mathrm{Bi}_{2} \mathrm{Se}_{3} @ \mathrm{Sec} \mathrm{NPs}$ & Effective biodegradability; promoting the body's immune function & Du et al. (2017) \\
\hline & $\begin{array}{l}\text { HA-functionalized gambogic acid (GA) loaded } \\
\mathrm{Bi}_{2} \mathrm{Se}_{3} \text { hollow nanocubes } \\
\text { (HNC-S-S-HA/GA) }\end{array}$ & $\begin{array}{l}\text { Effective accumulation and uptake by CD44 overexpressing cancer cells; } \\
\text { specifical drug releasing; avoiding heat damage } \\
\text { - }\end{array}$ & $\begin{array}{l}\text { Song et al. } \\
\text { (2019) }\end{array}$ \\
\hline & Heterogeneous & $\begin{array}{l}\text { satisfactory photothermal performance; enhanced radiosensitization } \\
\text { effectively inhibit the TNBC metastasis }\end{array}$ & $\begin{array}{l}\text { Fei Gao et al. } \\
(2020)\end{array}$ \\
\hline & $\mathrm{Bi}_{2} \mathrm{~S}_{3}-\mathrm{MoS}_{2} \mathrm{NPS}$ & - & \\
\hline & $\mathrm{MoS}_{2} / \mathrm{Bi}_{2} \mathrm{~S}_{3}-\mathrm{PEG}$ composite nanosheets & $\begin{array}{l}\text { Desirable photothermal performance, colloidal stability and } \\
\text { biocompatibility }\end{array}$ & $\begin{array}{l}\text { Wang et al. } \\
(2015)\end{array}$ \\
\hline & Core-Shell MnSe@ $\mathrm{Bi}_{2} \mathrm{Se}_{3}-\mathrm{PEG}$ & Additional MRI performance; photothermal-enhanced RT efficiency & $\begin{array}{l}\text { Song et al. } \\
(2015)\end{array}$ \\
\hline & $\mathrm{FeSe}_{2} / \mathrm{Bi}_{2} \mathrm{Se}_{3}-\mathrm{PEG}$ composite nanostructures & $\begin{array}{l}\text { Excellent compatibility, remarkable synergistic tumor destruction effect; no } \\
\text { appreciable toxic side effect }\end{array}$ & $\begin{array}{l}\text { Cheng et al. } \\
(2016)\end{array}$ \\
\hline
\end{tabular}

application in the field of biomedicine has been greatly restricted.

Bismuth, as an element with high atomic number $(Z=83)$, has surprising biocompatibility and been active in the biomedical field for hundreds of years. A variety of bismuth-based compounds have been widely used to treat diseases such as gastrohelcoma and bacterial infections (Peterson et al., 1996; Nomiya et al., 2004). Bismuth chalcogenides $\left(\mathrm{Bi}_{2} \mathrm{X}_{3}, X=\mathrm{S}, \mathrm{Se}\right)$ based nanodrugs have been favored in tumor RT due to their many unique characteristics: 1) low toxicity and high biological safety in vivo; 2) low cost and easy synthesis; 3) strong X-ray absorption (The X-ray attenuation coefficient of Bi element is $5.74>\mathrm{Au}=5.16>\mathrm{Pt}=4.99>\mathrm{Ta}=4.3 \mathrm{~cm}^{2} \mathrm{~g}^{-1}$ at $100 \mathrm{keV}$ ). After $\mathrm{Bi}_{2} \mathrm{X}_{3}$-based nanodrugs specifically enrich in the tumor area by passively or actively targeting effect, the tumor can be effectively killed at a lower X-ray dose, and the damage to other normal tissues can also be greatly reduced (Zhang et al., 2014; Song et al., 2017; Alejo-Martinez et al., 2019). Nevertheless, the RT effect of these nanodrugs is still greatly reduced by the hypoxic tumor microenvironment. Currently, many emerging $\mathrm{Bi}_{2} \mathrm{X}_{3}$ nanodrugs are developed to further improve the efficiency of RT, and have demonstrated very impressive tumor-killing effects. Here, a systematic review is provided to summarize the breakthrough progresses of $\mathrm{Bi}_{2} \mathrm{X}_{3}$ nanodrugs for overcoming the limitations of the tumor hypoxia microenvironment in the field of RT. Currently, three strategies have been developed to improve the $\mathrm{RT}$ efficiency of $\mathrm{Bi}_{2} \mathrm{X}_{3}$ nanodrugs (Figure 1; Table 1). Firstly, elaborately designed $\mathrm{Bi}_{2} \mathrm{X}_{3}$-based nanocomposites increase the supply of $\mathrm{O}_{2}$ to relieve the hypoxic state of the TME; the second strategy is non- $\mathrm{O}_{2}$ dependent $\mathrm{RT}$ : $\mathrm{Bi}_{2} \mathrm{X}_{3}$-based nanocomposites with distinctive heterojunction structure to promote the production of non- $\mathrm{O}_{2}$ dependent radicals; the third is photothermal-enhanced RT: local high temperature of the tumor site can not only relieve the hypoxic tumor microenvironment, but also increase the yield and speed of ROS production in RT. Finally, we discussed the challenges and prospects of bismuth chalcogenides nanocomposites in the field of cancer RT.

\section{High-Efficient $\mathrm{O}_{2}$-Supplied Radiotherapy}

Many well-designed $\mathrm{Bi}_{2} \mathrm{X}_{3}$-based nanocomposites have shown great potential in improving tumor hypoxia and RT efficiency. $\mathrm{Bi}_{2} \mathrm{X}_{3}$-based nanocomposites with ideal structure and morphology can be prepared through specific synthesis strategies due to their unique and flexible physical and chemical properties, such as hollow structure (Song et al., 2016; Zhang et al., 2020), mesoporous structure (Sun et al., 
2019; Yang et al., 2021), core-shell structure (Li et al., 2017; Li et al., 2018). For example, Song et al. (2016) prepared PEGylated hollow $\mathrm{Bi}_{2} \mathrm{Se}_{3}$ nanoparticles (PEG- $\mathrm{Bi}_{2} \mathrm{Se}_{3} \mathrm{NPs}$ ) through cation exchange reaction based on the Kirkendall effect. Perfluorocarbon, a highly efficient oxygen loading solvent, was then filled into the hollow structure of PEG- $\mathrm{Bi}_{2} \mathrm{Se}_{3}$ NPs (PEG$\left.\mathrm{Bi}_{2} \mathrm{Se}_{3} @ P F C @ \mathrm{O}_{2}\right)$. The oxygen carrying capacity of PEG- $\mathrm{Bi}_{2} \mathrm{Se}_{3} @$ PFC@O $\mathrm{O}_{2}$ was significantly higher than that of the hollow PEG$\mathrm{Bi}_{2} \mathrm{Se}_{3} \mathrm{NPs}$, up to $96.9 \pm 9.4 \mu \mathrm{mol} / \mathrm{g}$ of PEG- $\mathrm{Bi}_{2} \mathrm{Se}_{3}$. Moreover, the $\mathrm{O}_{2}$ retention time exceeded $1 \mathrm{~h}$, and the gradual release of $\mathrm{O}_{2}$ effectively improved the hypoxic microenvironment in the tumor site. At the same X-ray dose, the anti-tumor effect of PEG$\mathrm{Bi}_{2} \mathrm{Se}_{3} @ P F C @ \mathrm{O}_{2}$ was significantly better than that of PEG$\mathrm{Bi}_{2} \mathrm{Se}_{3}$ and $\mathrm{RT}$ group. Another effective strategy to improve tumor hypoxia is to convert the high concentration $\mathrm{H}_{2} \mathrm{O}_{2}$ into $\mathrm{O}_{2}$ in the tumor microenvironment (Zhang et al., 2018; Zhang et al., 2019; Yuzhu Yao et al., 2021). For example, Zhang et al. (2018) developed a $\mathrm{Bi}_{2} \mathrm{~S}_{3}$-albumin composite nanospheres combined with catalase (abbreviated as BSNSs-CAT) for cancer treatment. CAT at BSNSs-CAT efficiently catalyzed the conversion of $\mathrm{H}_{2} \mathrm{O}_{2}$ into $\mathrm{O}_{2}$ after BSNSs-CAT accumulated in tumor tissues through enhanced penetration and retention effect (EPR effect). The percentage of $\mathrm{O}_{2}$ saturation concentration treated with BSNSs-CAT increased significantly from $52.5 \%$ to about $59.2 \%$ in the tumor site. BSNSs-CAT + RT had the best tumor growth inhibition effect thanks to the strong reflective absorption of $\mathrm{Bi}$ and the improvement of the hypoxic microenvironment, followed by BSNSs + RT, then RT group. However, CAT, as a natural enzyme, is easily degraded and inactivated by proteases in vivo. Some catalase-mimick nanozymes can catalyze $\mathrm{H}_{2} \mathrm{O}_{2}$ to produce $\mathrm{H}_{2} \mathrm{O}$ and $\mathrm{O}_{2}$ (Dai et al., 2021). Very recently, Yuzhu Yao et al. (2021) developed a nanocomposite of $\mathrm{Bi}_{2} \mathrm{Se}_{3}, \mathrm{MnO}_{2}$ and bovine serum albumin $\left(\mathrm{Bi}_{2} \mathrm{Se}_{3}-\mathrm{MnO}_{2} @ \mathrm{BSA}\right)$ for RT. $\mathrm{MnO}_{2}$ showed high-efficiency catalase-like properties and excellent stability in vivo. Moreover, the CAT activity of $\mathrm{Bi}_{2} \mathrm{Se}_{3}-\mathrm{MnO}_{2} @ \mathrm{BSA}$ was 2.46 times higher than that of $\mathrm{MnO}_{2} @ \mathrm{BSA}$, because the $\mathrm{Mn}$ atoms of $\mathrm{Bi}_{2} \mathrm{Se}_{3}-\mathrm{MnO}_{2} @ \mathrm{BSA}$ was in an electron-rich state and easier to provide electrons for $\mathrm{H}_{2} \mathrm{O}_{2}$. The $\mathrm{Bi}_{2} \mathrm{Se}_{3}-\mathrm{MnO}_{2} @ \mathrm{BSA}+\mathrm{RT}$ group showed a stronger tumor-killing effect compared to the $\mathrm{MnO}_{2} @ \mathrm{BSA}+\mathrm{RT}$ group and the RT group in the in vivo treatments.

\section{Non- $\mathrm{O}_{2}$ Dependent Radiotherapy}

Non- $\mathrm{O}_{2}$ dependent RT has great advantages in RT, because it can directly avoid the RT resistance from the hypoxic microenvironment. As we all know, $\mathrm{Bi}$ chalcogenide compounds, as a narrow band gap semiconductor, can theoretically be excited by X-rays to generate free electrons and holes in the conduction band (CB) and valence band (VB), respectively (Meng et al., 2016; Waiskopf et al., 2016). These electron-hole pairs further react with $\mathrm{H}_{2} \mathrm{O}$ or $\mathrm{H}_{2} \mathrm{O}_{2}$ to generate highly cytotoxic hydroxyl radicals $(\cdot \mathrm{OH})$ to induce cancer cells apoptosis by intense oxidative damages. However, the generation of $\cdot \mathrm{OH}$ is significantly suppressed in $\mathrm{Bi}$ chalcogenide nanomaterials due to the rapid recombination of electron-hole pairs (Zhang et al., 2012). The heterojunction structure of $\mathrm{Bi}_{2} \mathrm{X}_{3}$ nanocomposites can separate electrons and holes to greatly reduce the recombination of electron and hole pairs (Wang et al., 2019; Abhari et al., 2020; Nosrati et al., 2022). For example, Wang et al. (2019) designed $\mathrm{Au}-\mathrm{Bi}_{2} \mathrm{~S}_{3}$ nanocomposites with Schottky-type heterostructures $\left(\mathrm{Au}-\mathrm{Bi}_{2} \mathrm{~S}_{3}\right.$ HNSCs) for non- $\mathrm{O}_{2}$ dependent RT. Au- $\mathrm{Bi}_{2} \mathrm{~S}_{3}$ HNSCs were prepared by in-situ growth of gold nanocrystals on $\mathrm{Bi}_{2} \mathrm{~S}_{3}$ nanorods. The Schottky barrier was a low interface voltage region on the metal-semiconductor boundary. Semiconductor $\mathrm{Bi}_{2} \mathrm{~S}_{3}$ generated low-energy electron-hole pairs under $\mathrm{X}$-ray irradiation in $\mathrm{Au}-\mathrm{Bi}_{2} \mathrm{~S}_{3}$ HNSCs, and then electrons and holes were effectively separated because the electrons were easily transferred to gold via Schottky barrier. The current response of $\mathrm{Au}-\mathrm{Bi}_{2} \mathrm{~S}_{3} \mathrm{HNSC}$ was 1.5-times higher than pure $\mathrm{Bi}_{2} \mathrm{~S}_{3}$ and the . $\mathrm{OH}$ production was 1.6-times than that of $\mathrm{Au}$ and $\mathrm{Bi}_{2} \mathrm{~S}_{3}$ mixture under X-ray irradiation. More importantly, the RT effect of Au$\mathrm{Bi}_{2} \mathrm{~S}_{3}$ HNSCs was significantly better than that of the pure $\mathrm{Bi}_{2} \mathrm{~S}_{3}$ group or the $\mathrm{Au}$ and $\mathrm{Bi}_{2} \mathrm{~S}_{3}$ mixture group both in the in vitro and in vivo experiments. In addition, $\mathrm{Bi}_{2} \mathrm{~S}_{3}-\mathrm{Au}$ Schottky-type heterostructures can be adopted as a multifunctional drug delivery platform to combine chemotherapy and RT. This combination therapy has shown great potential in improving the efficiency of RT and minimizing the systemic toxicity of chemotherapeutic drugs (Nadar et al., 2021). Very recently, Nosrati et al. (2022) developed a methotrexate and curcumin co-loaded BSA-encapsulated $\mathrm{Bi}_{2} \mathrm{~S}_{3}$-Au nanocomposite ( $\left.\mathrm{Bi}_{2} \mathrm{~S}_{3} @ B S A-A u-B S A-M T X-C U R\right)$ for the combined treatment of chemotherapy and RT. In $\mathrm{Bi}_{2} \mathrm{~S}_{3} @ B S A-A u-B S A-M T X-$ $\mathrm{CUR}, \mathrm{Bi}_{2} \mathrm{~S}_{3} @ \mathrm{BSA}$-Au heterojunctions enhance the generation of $\cdot \mathrm{OH}$ to increase the RT efficiency, while MTX efficiently promoted cellular uptake and interfere the biosynthesis of DNA of cancer cells. Interestingly, the combined treatment of chemotherapy and RT achieved a significant anti-cancer effect in vivo only under a single dose $\mathrm{Bi}_{2} \mathrm{~S}_{3} @ B S A-A u-B S A-M T X-C U R$ injection and one-time X-ray irradiation, and the tumors was completely eradicated after 20 days of treatment.

\section{Photothermal-Enhanced Radiotherapy}

In recent years, photothermal therapy (PTT), as a specific emerging cancer therapy, has been extensively researched in the field of tumor treatment (Liu et al., 2019; Danewalia and Singh, 2021). Many transition metal nanomaterials have been researched for PTT, such as $\mathrm{MoS}_{2}$-based nanomaterials (Jianling Wang et al., 2021), $\mathrm{CoS}_{2}$ nanomaterials (Wang et al., 2020a), copper-based nanomaterials (Ai et al., 2021; Wang et al., 2021b; Li et al., 2021), titanium-based nanomaterials (Wang et al., 2020b; Wang et al., 2021c), covalent organic frameworks (COFs) (Yao et al., 2021b), etc. Compared with above PTT agents, $\mathrm{Bi}_{2} \mathrm{X}_{3}$-based nanomaterials have been proven to be a kind of more excellent photosensitizers due to the strong near-infrared absorption performance and high photothermal conversion efficiency of $\mathrm{Bi}_{2} \mathrm{X}_{3}$ (Xie et al., 2016; Cheng et al., 2018). Local high temperature can directly increase the oxygen content of the tumor microenvironment by increasing blood flow in the tumor. Moreover, high temperature induced by PTT can facilitate the generation of $\mathrm{O}_{2}$-dependent ROS for $\mathrm{RT}$ by inhibiting the expression of hypoxia-inducible factor (HIF-1 $\alpha$ ) to increase oxygen concentration in tumor site. In addition, photothermal effects also interfere with DNA repair by 
reducing the expression of DNA repair related proteins (DNA repair enzymes, PARP, Rad 51), and downregulating angiogenic factors to inhibit tumor metastasis (Oei et al., 2015; Cheng et al., 2017). Therefore, the combination of photothermal therapy and $\mathrm{RT}$ is an effective radiosensitization strategy. For example, Wang et al. (2016) prepared ultra-small BSA-coated $\mathrm{Bi}_{2} \mathrm{~S}_{3}$ nanodots (BSA- $\mathrm{Bi}_{2} \mathrm{~S}_{3} \mathrm{NPs}$ ) for photothermal-enhanced RT. BSA-Bi $\mathrm{S}_{3} \mathrm{NPs}$ had the excellent $\mathrm{X}$-ray and photothermal response properties (the photothermal conversion efficiency was as high as $51 \%$ ). Moreover, The BSA- $\mathrm{Bi}_{2} \mathrm{~S}_{3}$ NPs with ultra-small size (about only $6 \mathrm{~nm}$ ) were more conducive to being taken up by tumor cells. Compared with the RT sensitization group $\left(\mathrm{Bi}_{2} \mathrm{~S}_{3}+\mathrm{X}\right.$-ray) or the PTT group $\left(\mathrm{Bi}_{2} \mathrm{~S}_{3}+\mathrm{NIR}\right)$, the $4 \mathrm{~T} 1$-tumor bearing mice treated with radio-photothermal combination therapy group $\left(\mathrm{Bi}_{2} \mathrm{~S}_{3}+\mathrm{X}-\right.$ ray + NIR) achieved complete tumor eradication, and the survival rate of mice reached $100 \%$ over 40 days after treatment. In addition, it is also extremely important to protect adjacent normal tissues from radiation damage during RT. Recently, Du et al. (2017) reported a $\mathrm{Bi}_{2} \mathrm{Se}_{3}$ nanoparticles modified with polyvinylpyrrolidone and selenocysteine (PVP-Bi $\mathrm{Se}_{3} @ \mathrm{Sec} \mathrm{NPs}$ ) for photothermal-enhanced RT. The photothermal effect of $\mathrm{Bi}_{2} \mathrm{Se}_{3}$ NPs effectively improved tumor hypoxia microenvironment to enhance the radiosensitivity of cancer cells. Moreover, the PVP$\mathrm{Bi}_{2} \mathrm{Se}_{3} @ S e c$ NPs were degraded in vivo, and part of the Se released from the NPs to enhance the body's immune function. Compared with RT, the PVP- $\mathrm{Bi}_{2} \mathrm{Se}_{3} @ S e c$ NPs group effectively protected the immune system, and the key cytokines level (like interleukin 6 and 2) were restored in the blood.

The efficiency of RT can be further increased by improving the photothermal conversion efficiency of the $\mathrm{Bi}_{2} \mathrm{X}_{3}$-based nanocomposites. Fox example, Fei Gao et al. (2020) developed heterogeneous $\mathrm{Bi}_{2} \mathrm{~S}_{3}-\mathrm{MoS}_{2}$ nanoparticles (BMNPs) for photothermal enhanced RT. BMNPs had a higher photothermal conversion efficiency than $\mathrm{Bi}_{2} \mathrm{~S}_{3}$ nanoparticles (BNPs) (35.8 vs 28.1\%). The BMNPs reduced the quasithreshold X-ray dose from 1.39 to $0.92 \mathrm{~Gy}$, and the sensitivity enhancement ratio increased by $17.9 \%$. The effect of NIR + RT + BMNP group was much better than that of RT group and RT + BMNPs group in the treatment of triple-negative breast cancer. The survival rate of mice in the NIR + RT + BMNP group was as high as $100 \%$ at 28 days after treatment, while the RT group and RT + BMNPs group had only 0 and $20 \%$, respectively. When the temperature of the tumor area rises, the tumor cells resisting heating-caused damage by up-regulating the expression of heat shock proteins (HSPs) (Ge Gao et al., 2020). Therefore, the photothermal enhanced RT can be further increased by inhibiting the activity of HSPs. Moreover, avoiding thermal damage and inflammation of adjacent normal tissues caused by hyperthermia also needs to be considered. Recently, Song et al. reported a hyaluronic acid (HA) modification and gambogic acid (GA) loaded hollow $\mathrm{Bi}_{2} \mathrm{Se}_{3}$ nanotube (HNC-ss-HA/GA) for low-temperature radio-photothermal combination therapy. HA ligands promoted the accumulation of HNC-ss-HA/GA in tumors due to its specifical affinity with CD44 receptor in cancer cells. Glutathione, one of the most important antioxidants in cells, is known to be overexpressed in cancer cells (Ding et al., 2021). Interestingly, the disulfide bond between
$\mathrm{HNC}$ and $\mathrm{HA}$ can be rapidly cleaved by glutathione to release GA. GA, as an effective inhibitor of HSPs, which could enhance the heat sensitivity of cancer cells (Su et al., 2021), thereby improve the efficacy of photothermal-enhanced RT. The combined therapy group (HNC-s-s-HA/GA $+\mathrm{NIR}+\mathrm{X}$-ray) demonstrated the strongest suppress tumor growth effect in vivo compared to other monotherapy groups (HNC-s-s-HA/ GA + NIR and HNC-s-s-HA/GA + X-ray).

\section{SUMMARY AND OUTLOOK}

In summary, this review summarizes the latest research progress of $\mathrm{Bi}_{2} \mathrm{X}_{3}$-based nanodrugs for $\mathrm{RT}$. $\mathrm{Bi}_{2} \mathrm{X}_{3}$-based nanodrugs have great clinical application prospects in the field of RT because of their super-high RT effect and biocompatibility. Nevertheless, there are still many challenges to overcome in achieving clinical translation of these treatment strategies. Firstly, the excellent RT effects of these $\mathrm{Bi}_{2} \mathrm{X}_{3}$-based nanodrugs are all achieved in mice models. However, the huge species difference between human and mice makes these nanodrugs face a big bottleneck for clinical translation. For example, mice tumor models generally take about 15 days, while human cancers often take months or even years. Therefore, the tumor microenvironment of human may be very different from that of mice models, which may lead to unsatisfactory clinical effects of $\mathrm{Bi}_{2} \mathrm{X}_{3}$-based nanodrugs. Therefore, from the perspective of clinical application, it is necessary to verify the radiosensitizing effect of $\mathrm{Bi}_{2} \mathrm{X}_{3}$-based nanodrugs in humanized animal models, such as the monkey models. Secondly, metabolic pathway of $\mathrm{Bi}_{2} \mathrm{X}_{3}$-based nanodrugs needs further study in vivo. As we all know, as a heavy metal element, excessive Bi may cause some side effects such as renal toxicity, brain toxicity and neurological decline, which can be attributed to the tendency of Bi to bind to sulfhydryl groups in many important enzymes in the human body, resulting in the denaturation of enzymes and destroys its functionality. At present, most of the metabolism and toxicity of $\mathrm{Bi}_{2} \mathrm{X}_{3}$-based nanodrugs have only been done for about a month, and the longer-term toxicity and metabolic mechanisms still need to be further explored. Therefore, exploring biodegradable and clearable $\mathrm{Bi}_{2} \mathrm{X}_{3}$-based nanodrugs is of great significance for thier clinical translation (Wang et al., 2021a). Fortunately, there is rare $\mathrm{Bi}$ element in the human body itself. Therefore, the distribution, metabolism, and excretion process of $\mathrm{Bi}_{2} \mathrm{X}_{3}$ based nanodrugs can be easily tracked by the content and valence of $\mathrm{Bi}$ in vivo. Thirdly, the large-scale and controllable preparation of $\mathrm{Bi}_{2} \mathrm{X}_{3}$-based nanodrugs need to be further optimized. In commercial preparation, it is necessary to maintain precise control of the size, morphology, charge, and composition of nanomaterials to ensure uniformity and strict quality control. Therefore, exploring a simpler, faster, more precise and controllable synthesis process is vital for the clinical translation and commercial production of $\mathrm{Bi}_{2} \mathrm{X}_{3}$-based nanodrugs in the field of RT. Nevertheless, $\mathrm{Bi}_{2} \mathrm{X}_{3}$-based nanodrugs still have great clinical application prospects of RT. As mentioned earlier, NBTXR3 based on $\mathrm{HfO}_{2}$ have shown excellent effects in clinical phase III. In theory, $\mathrm{Bi}_{2} \mathrm{X}_{3}$-based 
nanodrugs have stronger biocompatibility and radiosensitization effect than $\mathrm{HfO}_{2}$ nanoparticles. We believe that $\mathrm{Bi}_{2} \mathrm{X}_{3}$-based nanodrugs will achieve true clinical RT treatment with the joint efforts of scientists from multiple disciplines such as chemistry, medicine, and biology in the near future.

\section{AUTHOR CONTRIBUTIONS}

All authors listed have made a substantial, direct, and intellectual contribution to the work and approved it for publication.

\section{REFERENCES}

Abhari, F., Charmi, J., Rezaeejam, H., Karimimoghaddam, Z., Nosrati, H., Danafar, H., et al. (2020). Folic Acid Modified Bismuth Sulfide and Gold Heterodimers for Enhancing Radiosensitization of Mice Tumors to X-ray Radiation. ACS Sustain. Chem. Eng. 8 (13), 5260-5269. doi:10.1021/ acssuschemeng.0c00182

Ai, K., Huang, J., Xiao, Z., Yang, Y., Bai, Y., and Peng, J. (2021). Localized Surface Plasmon Resonance Properties and Biomedical Applications of Copper Selenide Nanomaterials. Mater. Today Chem. 20, 100402. doi:10.1016/j. mtchem.2020.100402

Alejo-Martinez, H., Sevilla-Moreno, A. C., Ondo-Mendéz, A., Quintero, J. H., and Páez, C. J. (2019). Comparison of Bi 2 S 3 and Ta $2 \mathrm{O} 5$ as Alternative Materials to Gold in Nanoparticles Used as Agents to Increase the Dose in Radiotherapy. J. Phys. Conf. Ser. 1247 (1), 012050. doi:10.1088/1742-6596/1247/1/012050

Begg, A. C., Stewart, F. A., and Vens, C. (2011). Strategies to Improve Radiotherapy with Targeted Drugs. Nat. Rev. Cancer 11 (4), 239-253. doi:10.1038/nrc3007

Bentzen, S. M. (2006). Preventing or Reducing Late Side Effects of Radiation Therapy: Radiobiology Meets Molecular Pathology. Nat. Rev. Cancer 6 (9), 702-713. doi:10.1038/nrc1950

Bonvalot, S., Rutkowski, P. L., Thariat, J., Carrère, S., Ducassou, A., Sunyach, M. P., et al. (2019). NBTXR3, a First-In-Class Radioenhancer Hafnium Oxide Nanoparticle, Plus Radiotherapy versus Radiotherapy Alone in Patients with Locally Advanced Soft-Tissue Sarcoma (Act.In.Sarc): a Multicentre, Phase 2-3, Randomised, Controlled Trial. Lancet Oncol. 20 (8), 1148-1159. doi:10.1016/ S1470-2045(19)30326-2

Cheng, L., Shen, S., Shi, S., Yi, Y., Wang, X., Song, G., et al. (2016). FeSe2-Decorated Bi2Se3 Nanosheets Fabricated via Cation Exchange for Chelator-free $64 \mathrm{Cu}-$ Labeling and Multimodal Image-Guided Photothermal-Radiation Therapy. Adv. Funct. Mater. 26 (13), 2185-2197. doi:10.1002/adfm.201504810

Cheng, X., Yong, Y., Dai, Y., Song, X., Yang, G., Pan, Y., et al. (2017). Enhanced Radiotherapy Using Bismuth Sulfide Nanoagents Combined with Photothermal Treatment. Theranostics 7 (17), 4087-4098. doi:10.7150/thno.20548

Cheng, Y., Chang, Y., Feng, Y., Jian, H., Tang, Z., and Zhang, H. (2018). Deep-Level Defect Enhanced Photothermal Performance of Bismuth Sulfide-Gold Heterojunction Nanorods for Photothermal Therapy of Cancer Guided by Computed Tomography Imaging. Angew. Chem. Int. Ed. Engl. 57 (1), 246-251. doi:10.1002/anie.201710399

Dai, Y., Ding, Y., and Li, L. (2021). Nanozymes for Regulation of Reactive Oxygen Species and Disease Therapy. Chin. Chem. Lett. 32 (9), 2715-2728. doi:10.1016/ j.cclet.2021.03.036

Danewalia, S. S., and Singh, K. (2021). Bioactive Glasses and Glass-Ceramics for Hyperthermia Treatment of Cancer: State-Of-Art, Challenges, and Future Perspectives. Mater. Today Bio 10, 100100. doi:10.1016/j.mtbio.2021.100100

De Martino, M., Daviaud, C., and Vanpouille-Box, C. (2021). Radiotherapy: An Immune Response Modifier for Immuno-Oncology. Semin. Immunol. 52, 101474. doi:10.1016/j.smim.2021.101474

Ding, Y., Dai, Y., Wu, M., and Li, L. (2021). Glutathione-mediated Nanomedicines for Cancer Diagnosis and Therapy. Chem. Eng. J. 426, 128880. doi:10.1016/j.cej. 2021.128880

Du, J., Gu, Z., Yan, L., Yong, Y., Yi, X., Zhang, X., et al. (2017). Poly(Vinylpyrollidone)- and Selenocysteine-Modified Bi2 Se3 Nanoparticles

\section{FUNDING}

This work was supported by the National Natural Science Foundation of China (Nos. 21974134 and 81974508), the Hunan Science Fund for Distinguished Young Scholar of China (No. 2021JJ10067), Innovation-Driven Project of Central South University (No. 202045005), Hunan Provincial Natural Science Foundation of China (No. 2021JJ31066), Changsha Science and Technology Project (No. kq2001048), Key Research Project of Ningxia Hui Autonomous Region in 2021 of China (Major Project) (No. 2021BEG01001).

Enhance Radiotherapy Efficacy in Tumors and Promote Radioprotection in Normal Tissues. Adv. Mater. 29 (34), 1701268. doi:10.1002/adma.201701268

Evans, S. M., Jenkins, W. T., Shapiro, M., and Koch, C. J. (1997). "Evaluation of the Concept of "Hypoxic Fraction" as a Descriptor of Tumor Oxygenation Status," in Oxygen Transport to Tissue XVIII. Editors E. M. Nemoto, J. C. LaManna, C. Cooper, D. Delpy, K. Groebe, T. K. Hunt, et al. (Boston, MA: Springer US), 215-225. doi:10.1007/978-1-4615-5865-1_26

Gao, F., Wang, D., Zhang, T., Ghosal, A., Guo, Z., Miao, Y., et al. (2020). Facile Synthesis of Bi2S3-MoS2 Heterogeneous Nanoagent as Dual Functional Radiosensitizer for Triple Negative Breast Cancer Theranostics. Chem. Eng. J. 395, 125032. doi:10.1016/j.cej.2020.125032

Gao, G., Jiang, Y. W., Guo, Y., Jia, H. R., Cheng, X., Deng, Y., et al. (2020). EnzymeMediated Tumor Starvation and Phototherapy Enhance Mild-Temperature Photothermal Therapy. Adv. Funct. Mater. 30 (16), 1909391. doi:10.1002/adfm. 201909391

Le Caër, S. (2011). Water Radiolysis: Influence of Oxide Surfaces on H2 Production under Ionizing Radiation. Water 3 (1), 235-253. doi:10.3390/w3010235

Li, Y., Sun, Y., Cao, T., Su, Q., Li, Z., Huang, M., et al. (2017). A Cation-Exchange Controlled Core-Shell MnS@Bi2S3 Theranostic Platform for Multimodal Imaging Guided Radiation Therapy with Hyperthermia Boost. Nanoscale 9 (38), 14364-14375. doi:10.1039/c7nr02384g

Li, L., Lu, Y., Jiang, C., Zhu, Y., Yang, X., Hu, X., et al. (2018). Actively Targeted Deep Tissue Imaging and Photothermal-Chemo Therapy of Breast Cancer by Antibody-Functionalized Drug-Loaded X-Ray-Responsive Bismuth Sulfide@ Mesoporous Silica Core-Shell Nanoparticles. Adv. Funct. Mater. 28 (5), 1704623. doi:10.1002/adfm.201704623

Li, X., Yuan, H. J., Tian, X. M., Tang, J., Liu, L. F., and Liu, F. Y. (2021). Biocompatible Copper Sulfide-Based Nanocomposites for Artery Interventional Chemo-Photothermal Therapy of Orthotropic Hepatocellular Carcinoma. Mater. Today Bio 12, 100128. doi:10.1016/j.mtbio.2021.100128

Liu, Y., Bhattarai, P., Dai, Z., and Chen, X. (2019). Photothermal Therapy and Photoacoustic Imaging via Nanotheranostics in Fighting Cancer. Chem. Soc. Rev. 48 (7), 2053-2108. doi:10.1039/c8cs00618k

Liu, J., Zhang, J., Song, K., Du, J., Wang, X., Liu, J., et al. (2021). Tumor Microenvironment Modulation Platform Based on Composite Biodegradable Bismuth-Manganese Radiosensitizer for Inhibiting Radioresistant Hypoxic Tumors. Small 17 (34), 2101015. doi:10.1002/smll.202101015

Mao, F., Wen, L., Sun, C., Zhang, S., Wang, G., Zeng, J., et al. (2016). Ultrasmall Biocompatible Bi2Se3 Nanodots for Multimodal Imaging-Guided Synergistic Radiophotothermal Therapy against Cancer. ACS Nano 10 (12), 11145-11155. doi:10.1021/acsnano.6b06067

Meng, X., Liu, L., Ouyang, S., Xu, H., Wang, D., Zhao, N., et al. (2016). Nanometals for Solar-To-Chemical Energy Conversion: From Semiconductor-Based Photocatalysis to Plasmon-Mediated Photocatalysis and PhotoThermocatalysis. Adv. Mater. 28 (32), 6781-6803. doi:10.1002/adma. 201600305

Nadar, R. A., Franssen, G. M., Van Dijk, N. W. M., Codee-van der Schilden, K., de Weijert, M., Oosterwijk, E., et al. (2021). Bone Tumor-Targeted Delivery of Theranostic 195mPt-Bisphosphonate Complexes Promotes Killing of Metastatic Tumor Cells. Mater. Today Bio 9, 100088. doi:10.1016/j.mtbio. 2020.100088

Nomiya, K., Sekino, K., Ishikawa, M., Honda, A., Yokoyama, M., Chikaraishi Kasuga, N., et al. (2004). Syntheses, crystal Structures and Antimicrobial 
Activities of Monomeric 8-coordinate, and Dimeric and Monomeric 7coordinate Bismuth(III) Complexes with Tridentate and Pentadentate Thiosemicarbazones and Pentadentate Semicarbazone Ligands. J. Inorg. Biochem. 98 (4), 601-615. doi:10.1016/j.jinorgbio.2004.01.011

Nosrati, H., Attari, E., Abhari, F., Barsbay, M., Ghaffarlou, M., Mousazadeh, N., et al. (2022). Complete Ablation of Tumors Using Synchronous Chemoradiation with Bimetallic Theranostic Nanoparticles. Bioactive Mater. 7, 74-84. doi:10.1016/j.bioactmat.2021.05.015

Oei, A. L., Vriend, L. E., Crezee, J., Franken, N. A., and Krawczyk, P. M. (2015). Effects of Hyperthermia on DNA Repair Pathways: One Treatment to Inhibit Them All. Radiat. Oncol. 10 (1), 165. doi:10.1186/s13014-0150462-0

Peng, C., Liang, Y., Chen, Y., Qian, X., Luo, W., Chen, S., et al. (2020). Hollow Mesoporous Tantalum Oxide Based Nanospheres for Triple Sensitization of Radiotherapy. ACS Appl. Mater. Inter. 12 (5), 5520-5530. doi:10.1021/acsami. 9 b20053

Peterson, W. L., Ciociola, A. A., Sykes, D. L., McSorley, D. J., and Webb, D. D. (1996). Ranitidine Bismuth Citrate Plus Clarithromycin Is Effective for Healing Duodenal Ulcers, Eradicating H. pylori and Reducing Ulcer Recurrence. RBC $H$. pylori Study Group. Aliment. Pharmacol. Ther. 10 (3), 251-261. doi:10.1111/j. 0953-0673.1996.00251.x

Song, G., Liang, C., Gong, H., Li, M., Zheng, X., Cheng, L., et al. (2015). Core-Shell MnSe@Bi2 Se3 Fabricated via a Cation Exchange Method as Novel Nanotheranostics for Multimodal Imaging and Synergistic Thermoradiotherapy. Adv. Mater. 27 (40), 6110-6117. doi:10.1002/adma. 201503006

Song, G., Liang, C., Yi, X., Zhao, Q., Cheng, L., Yang, K., et al. (2016). Perfluorocarbon-Loaded Hollow Bi2Se3 Nanoparticles for Timely Supply of Oxygen under Near-Infrared Light to Enhance the Radiotherapy of Cancer. Adv. Mater. 28 (14), 2716-2723. doi:10.1002/adma.201504617

Song, Z., Chang, Y., Xie, H., Yu, X.-F., Chu, P. K., and Chen, T. (2017). Decorated Ultrathin Bismuth Selenide Nanosheets as Targeted Theranostic Agents for In Vivo Imaging Guided Cancer Radiation Therapy. NPG Asia Mater. 9 (10), e439. doi:10.1038/am.2017.167

Song, Y., Wang, Y., Zhu, Y., Cheng, Y., Wang, Y., Wang, S., et al. (2019). Biomodal Tumor-Targeted and Redox-Responsive Bi2 Se3 Hollow Nanocubes for MSOT/ CT Imaging Guided Synergistic Low-Temperature Photothermal Radiotherapy. Adv. Healthc. Mater. 8 (16), e1900250. doi:10.1002/adhm. 201900250

Su, X., Cao, Y., Liu, Y., Ouyang, B., Ning, B., Wang, Y., et al. (2021). Localized Disruption of Redox Homeostasis Boosting Ferroptosis of Tumor by Hydrogel Delivery System. Mater. Today Bio 12, 100154. doi:10.1016/j.mtbio.2021. 100154

Sun, L., Hou, M., Zhang, L., Qian, D., Yang, Q., Xu, Z., et al. (2019). PEGylated mesoporous Bi2S3 nanostars loaded with chlorin e6 and doxorubicin for fluorescence/CT imaging-guided multimodal therapy of cancer. Nanomedicine 17, 1-12. doi:10.1016/j.nano.2018.12.013

Tang, W., Dong, Z., Zhang, R., Yi, X., Yang, K., Jin, M., et al. (2019). Multifunctional Two-Dimensional Core-Shell MXene@Gold Nanocomposites for Enhanced Photo-Radio Combined Therapy in the Second Biological Window. ACS Nano 13 (1), 284-294. doi:10.1021/ acsnano.8b05982

Wang, J., Sui, L., Huang, J., Miao, L., Nie, Y., Wang, K., et al. (2021). MoS2-based Nanocomposites for Cancer Diagnosis and Therapy. Bioact Mater. 6 (11), 4209-4242. doi:10.1016/j.bioactmat.2021.04.021

Waiskopf, N., Ben-Shahar, Y., Galchenko, M., Carmel, I., Moshitzky, G., Soreq, H., et al. (2016). Photocatalytic Reactive Oxygen Species Formation by Semiconductor-Metal Hybrid Nanoparticles. Toward Light-Induced Modulation of Biological Processes. Nano Lett. 16 (7), 4266-4273. doi:10. 1021/acs.nanolett.6b01298

Wang, S., Li, X., Chen, Y., Cai, X., Yao, H., Gao, W., et al. (2015). A Facile One-Pot Synthesis of a Two-Dimensional MoS2/Bi2S3 Composite Theranostic Nanosystem for Multi-Modality Tumor Imaging and Therapy. Adv. Mater. 27 (17), 2775-2782. doi:10.1002/adma.201500870

Wang, Y., Wu, Y., Liu, Y., Shen, J., Lv, L., Li, L., et al. (2016). BSA-mediated Synthesis of Bismuth Sulfide Nanotheranostic Agents for Tumor Multimodal Imaging and Thermoradiotherapy. Adv. Funct. Mater. 26 (29), 5335-5344. doi:10.1002/adfm.201601341
Wang, X., Zhang, C., Du, J., Dong, X., Jian, S., Yan, L., et al. (2019). Enhanced Generation of Non-oxygen Dependent Free Radicals by Schottky-type Heterostructures of Au-Bi2S3 Nanoparticles via X-ray-Induced Catalytic Reaction for Radiosensitization. ACS Nano 13 (5), 5947-5958. doi:10.1021/ acsnano.9b01818

Wang, X., Zhong, X., Zha, Z., He, G., Miao, Z., Lei, H., et al. (2020). Biodegradable CoS2 Nanoclusters for Photothermal-Enhanced Chemodynamic Therapy. Appl. Mater. Today 18, 100464. doi:10.1016/j. apmt.2019.100464

Wang, X., Wang, X., Zhong, X., Li, G., Yang, Z., Gong, Y., et al. (2020). V-TiO2 Nanospindles with Regulating Tumor Microenvironment Performance for Enhanced Sonodynamic Cancer Therapy. Appl. Phys. Rev. 7 (4), 041411. doi:10.1063/5.0027606

Wang, X., Zhong, X., Li, J., Liu, Z., and Cheng, L. (2021). Inorganic Nanomaterials with Rapid Clearance for Biomedical Applications. Chem. Soc. Rev. 50 (15), 8669-8742. doi:10.1039/d0cs00461h

Wang, X., Shi, Q., Zha, Z., Zhu, D., Zheng, L., Shi, L., et al. (2021). Copper SingleAtom Catalysts with Photothermal Performance and Enhanced Nanozyme Activity for Bacteria-Infected Wound Therapy. Bioact Mater. 6 (12), 4389-4401. doi:10.1016/j.bioactmat.2021.04.024

Wang, X., Zhong, X., and Cheng, L. (2021). Titanium-based Nanomaterials for Cancer Theranostics. Coord. Chem. Rev. 430, 213662. doi:10.1016/j.ccr.2020. 213662

Wu, M., Ding, Y., and Li, L. (2019). Recent Progress in the Augmentation of Reactive Species with Nanoplatforms for Cancer Therapy. Nanoscale 11 (42), 19658-19683. doi:10.1039/c9nr06651a

Xie, H., Li, Z., Sun, Z., Shao, J., Yu, X. F., Guo, Z., et al. (2016). Metabolizable Ultrathin Bi2 Se3 Nanosheets in Imaging-Guided Photothermal Therapy. Small 12 (30), 4136-4145. doi:10.1002/smll.201601050

Xie, J., Gong, L., Zhu, S., Yong, Y., Gu, Z., and Zhao, Y. (2019). Emerging Strategies of Nanomaterial-Mediated Tumor Radiosensitization. Adv. Mater. 31 (3), e1802244. doi:10.1002/adma.201802244

Xue, J., Duosiken, D., Zhong, S., Cao, J. J., Hu, L. Y., Sun, K., et al. (2021). The Dependence of Radio-Sensitization Efficiency on Mitochondrial Targeting with NaGdF4:Yb,Er Nanoparticles. Acta Biomater. 131, 508-518. doi:10.1016/j. actbio.2021.06.041

Yang, C., Chang, M., Yuan, M., Jiang, F., Ding, B., Zhao, Y., et al. (2021). NIRTriggered Multi-Mode Antitumor Therapy Based on $\mathrm{Bi} 2 \mathrm{Se} 3 / \mathrm{Au}$ Heterostructure with Enhanced Efficacy. Small 17 (28), 2100961. doi:10. 1002/smll.202100961

Yao, S., Zhao, X., Wan, X., Wang, X., Huang, T., Zhang, J., et al. (2021). $\pi-\pi$ Conjugation Promoted Nanocatalysis for Cancer Therapy Based on a Covalent Organic Framework. Mater. Horiz 8 (12), 3457-3467. doi:10.1039/ dlmh01273h

Yao, S., Liu, Z., and Li, L. (2021). Recent Progress in Nanoscale Covalent Organic Frameworks for Cancer Diagnosis and Therapy. Nanomicro Lett. 13 (1), 176. doi:10.1007/s40820-021-00696-2

Yao, Y., Li, P., He, J., Wang, D., Hu, J., and Yang, X. (2021). Albumin-Templated Bi2Se3-MnO2 Nanocomposites with Promoted Catalase-like Activity for Enhanced Radiotherapy of Cancer. ACS Appl. Mater. Inter. 13 (24), 28650-28661. doi:10.1021/acsami.1c05669

Zang, Y., Gong, L., Mei, L., Gu, Z., and Wang, Q. (2019). Bi2WO6 Semiconductor Nanoplates for Tumor Radiosensitization through High- Z Effects and Radiocatalysis. ACS Appl. Mater. Inter. 11 (21), 18942-18952. doi:10.1021/ acsami.9b03636

Zhang, Z., Wang, W., Wang, L., and Sun, S. (2012). Enhancement of Visible-Light Photocatalysis by Coupling with Narrow-Band-Gap Semiconductor: A Case Study on Bi2S3/Bi2WO6. ACS Appl. Mater. Inter. 4 (2), 593-597. doi:10.1021/ am2017199

Zhang, X.-D., Chen, J., Min, Y., Park, G. B., Shen, X., Song, S.-S., et al. (2014). Metabolizable Bi2Se3Nanoplates: Biodistribution, Toxicity, and Uses for Cancer Radiation Therapy and Imaging. Adv. Funct. Mater. 24 (12), 1718-1729. doi:10.1002/adfm.201302312

Zhang, Q., Chen, J., Ma, M., Wang, H., and Chen, H. (2018). A Bioenvironment-Responsive Versatile Nanoplatform Enabling Rapid Clearance and Effective Tumor Homing for Oxygen-Enhanced Radiotherapy. Chem. Mater. 30 (15), 5412-5421. doi:10.1021/acs. chemmater.8b02251 
Zhang, L., Chen, Q., Zou, X., Chen, J., Hu, L., Dong, Z., et al. (2019). Intelligent Protein-Coated Bismuth Sulfide and Manganese Oxide Nanocomposites Obtained by Biomineralization for Multimodal Imaging-Guided Enhanced Tumor Therapy. J. Mater. Chem. B 7 (34), 5170-5181. doi:10.1039/ c9tb00991d

Zhang, C., Li, D., Pei, P., Wang, W., Chen, B., Chu, Z., et al. (2020). Rod-based Urchin-like Hollow Microspheres of Bi2S3: Facile Synthesis, Photo-Controlled Drug Release for Photoacoustic Imaging and Chemo-Photothermal Therapy of Tumor Ablation. Biomaterials 237, 119835. doi:10.1016/j.biomaterials.2020. 119835

Zhao, T., Wu, W., Sui, L., Huang, Q., Nan, Y., Liu, J., et al. (2022). Reactive Oxygen Species-Based Nanomaterials for the Treatment of Myocardial Ischemia Reperfusion Injuries. Bioactive Mater. 7, 47-72. doi:10.1016/j.bioactmat. 2021.06.006

Zhu, Y., Zhao, T., Liu, M., Wang, S., Liu, S., Yang, Y., et al. (2022). Rheumatoid Arthritis Microenvironment Insights into Treatment Effect of Nanomaterials. Nano Today 42, 101358. doi:10.1016/j.nantod.2021.101358
Conflict of Interest: The authors declare that the research was conducted in the absence of any commercial or financial relationships that could be construed as a potential conflict of interest.

Publisher's Note: All claims expressed in this article are solely those of the authors and do not necessarily represent those of their affiliated organizations, or those of the publisher, the editors and the reviewers. Any product that may be evaluated in this article, or claim that may be made by its manufacturer, is not guaranteed or endorsed by the publisher.

Copyright (c) 2022 Huang, Huang, Liu, Chen and Ai. This is an open-access article distributed under the terms of the Creative Commons Attribution License (CC BY). The use, distribution or reproduction in other forums is permitted, provided the original author(s) and the copyright owner(s) are credited and that the original publication in this journal is cited, in accordance with accepted academic practice. No use, distribution or reproduction is permitted which does not comply with these terms. 